\title{
2007 KÜRESEL FİNANSAL KRİZ VE GÖLGE BANKACILIK
}

\author{
Suat OKTAR*，Nadir EROĞLU**
}

\section{$\ddot{O}_{z e t}$}

2008 küresel finans krizi koşullarında birçok yeni finansal türev enstrümanı işleme konu yapılmuş ve bu enstrümanların çeşitliliği hızla artmıştır. Finans piyasalarında özellikle konut kredisinin ağırlık kazanması, hem finans hem de reel sektöre yönelik yeni bir oluşumun da altyapısını hazırlamıştır. Gerçekten de, söz konusu konjonktürde geleneksel bankacıllğın yanında, piyasanın denetim ve düzenleme boşluğundan yararlanan, esnekliğe ve serbestliğe sahip, yeni bir bankacıllk alanı ortaya çıkmıştır. Sanal ya da gölge bankactlık olarak nitelendirilen ve 2008 krizinin doğrudan nedeni olmasa da, krizin derinleşmesine yol açan bu bankacılık halen günümüz bankacilığında küçümsenmeyecek bir ağırllk kazanmış bulunmaktadır. Bu çalışmada gölge bankacılığın doğuşu, kavramsal çerçevesi, olumlu ve olumsuz yönleri ele alınmış, en sonunda da bu bankacıllğın düzenlenmesine yönelik önerilerde bulunulmuştur.

Anahtar Kelimeler: Finansal Kriz, Kredi Aracılı̆̆g, Gölge Bankacıllk

JEL Sinıflaması: G01, G20, G28

\section{GLOBAL FINANCIAL CRISIS AND SHADOW BANKING}

\section{Abstract}

During the 2008 financial crisis, in the financial markets, the number and the variety of financial derivatives increased significantly. Increasing importance of mortgage credits has created a new infrastructure towards financial and real sectors. Under such circumstances, in addition to traditional banking system, a new flexible and free banking system which relies on lags in the regulation and inspection processes has emerged. Although it is not one of the direct causes of 2008 crises, virtual or shadow banking has a significant role in overall banking system. In this study, the emergence of shadow banking, its conceptual framework has been examined in regard to its postive and negative aspects and at the end, suggestions were proposed towards the regulation of shadow banking system.

Keywords: Financial Crisis, Credit Intermediation, Shadow Banking

JEL Classification: G01, G20, G28

\footnotetext{
* Prof. Dr., Marmara Üniversitesi, İktisat Fakültesi, İktisat Bölümü Öğretim Üyesi, soktar@marmara.edu.tr

** Prof. Dr., Marmara Üniversitesi, İktisat Fakültesi, İktisat Bölümü Öğretim Üyesi, neroglu@marmara.edu.tr
} 


\section{2008 Küresel Kriz Konjonktürü ve Gölge Bankacılığın Doğuşu}

Finansal küreselleşme sürecinde finans piyasalarında serbestleşmenin ${ }^{1}$ ivme kazanması, piyasalarda riski tolere etmek amacıyla çıkarılan finansal türev araçlarının çeşitlenmiş olması, son yıllarda en önemli gelişmeler olarak dikkati çekmektedir. $\mathrm{Ne}$ var ki, finansal araçların denetim dışı sirkülasyonu hem piyasalar hem de finansal aktörler için risk faktörünü öne çıkarmıştır. Gerçekten de, finansal inovasyonlar sonucu ortaya çıkan ve yatırımcının riskini azaltma (hedging) odaklı türev enstrümanlar piyasada denetim eksikliğinden ve serbestlikten yararlanarak zamanla birer risk unsuru olmuşlardır. $^{2}$

Hedge fonların yatırımcıyı riskten korumak gibi bir işlevi olsa da, gerçekte bu fonlar yüksek getiri peşinde koşan ve el değiştiren enstrüman ve yatırım araçları olma özelliğini taşımaktadır. Çünkü doğaları gereği bu fonlar pozisyon alma esasına dayanır. Yani, aradaki farktan büyük kâr elde etme avantajını öne çıkarır. Bu bir bakıma, büyük balığın küçük balığın peşinde koşmasıdır. Serbest piyasa düzeni içerisinde manipüle edilmiş yönetimlerle geliştirilen bu işlem kısaca "Short Sell" olarak bilinir. ${ }^{3}$ Bu yöntem, belirli bir değerin borç ve bono şeklinde kağıtların çeşitli spekülasyonlarla gerçek değerinin çok üstünde dönüştürülmesine ve birçok kez el değiştirmesine dayanmaktadır. ${ }^{4}$ Üstelik, bu fonlar denetim hükümlerine ve herhangi bir kısıta bağlı olmadan sadece sermayeyi korumayı amaçlar. ${ }^{5} \mathrm{Bu}$ özellikleri itibariyle hedge fonlar büyük bir güce sahiptirler. Nitekim, Paul Krugman, hedge fonlar için evrenin efendileri yakıştırmasını yapmaktadır. ${ }^{6}$

Birleşik Amerika'nın 2000'li yılların başından itibaren petrol fiyatları artıkça karşılıksız olarak dolar basması piyasalarda likidite bolluğu yaratmışır. Piyasalardaki bu gelişme hedge fonları benzeri riskli işlemleri ve yatırımları adeta pompalamıştır. FED'in 2003 Haziranında faizi son elli yılın en düşük seviyesi olan yüzde 1'e düşürmesi de değirmene su taşımıştır. Bu durum, en çok emlak alımı için verilen Mortgage kredilerinde görülmüştür.

1 Finansal serbestleşmeyle ilgili olarak bkz. G.L. Kaminsky ve S.L. Secmukler, Short-Run Pain, Long Run Gain: The Effects of Financial Liberalization, IMF Working Paper, WP/03/34, Washington, DC: International Monetary Fund, 2003; Aslı Kunt Demirgüç, ve Enrica Detragiache, Financial Liberalization and Fiinancial Fragility, Policy Research Working Paper, No:1917, World Bank, Washington, 1998

2 Ömer Tuğsal Doruk ve Yusuf Can Şahintürk,“2008 Küresel Krizde Gölge Bankacılık Sektörünün Rolü ve Reel Sektör ve Finansal Sektör İlişkisi: Türkiye’nin Finansal Kırılganlık Hipotezi Çerçevesinde Bir İnceleme”, Uluslararası Finans Sempozyumu 2010 Bildiri Kitabı ss.523-545, Marmara Üniversitesi Yayınları:İstanbul, 2010

3 Frederic S. Mishkin ve Stanley Eakins, Financial Markets and Institutions, Fourth Edition, Addison Wesley, 2003, s. 578

4 Ramazan Kurtoğlu, Küresel Ekonomik Kriz ve Yeni Dünya Düzeni, İstasyon Yayınları, İstanbul, 2011, s. 132

5 Filippo Stefanini, Investment Strategies of Hedge Funds, West Sussex, John Wiley \& Sons Inc., 2006, s.1

6 Paul Krugman, Bunalım Ekonomisine Geri Dönüş ve Küresel Kriz, Çev: Neşenur Domaniç, Literatür Yayınları, 60, İstanbul, 2001, s. 127 
Başlangıçta yüksek gelirli kesimlere açılan kredilerin, 2004 yılından itibaren yapılan düzenlemeyle eşik altı(sub-prime) olarak ifade edilen düzenli geliri ya da varlığı olmayan bireylere de kullandırılması konut piyasasında oluşan balonun şişmesine yol açmıştır. Sadece 2001-2006 yılları arasında kullandırılan eşik altı konut kredilerinin hacmi 2.5 trilyon doları aşmıştır. ${ }^{7}$ Bu parasal büyüklük toplam konut kredilerinin yüzde 25 'ine denk düşmektedir. Ancak artan talep sonucunda emlak fiyatlarının düşüp, sub-prime kredi kullananlar borçlarını geri ödeyemeyecek duruma gelince balon patlamış ve saadet zinciri kırılmıştır. Konut kredisine olan talep artışı, başlangıçta masum bir amaç olan konut sahipliğinden çok, para kazanmanın kolay bir yolu olarak görülmesinden kaynaklanmıştır. Nitekim, Amerika konut sahipleri, ev fiyatlarının her yıl yüzde 20 artacağı masalına coşkuyla sarılmışlar ve bu inanca dayanarak daha çok ve daha çok borçlanmışlardır. ${ }^{8}$

Gerçekten de, bankalar tarafından yaratılan krediler menkul kıymetleştirme yoluyla paketlenerek diğer yatırımcılara satılmıştır. Sadece 2007 yılında kredi kartı, otomobil kredisi ve öğrenci kredilerinden oluşan varlığa dayalı menkul kıymet (asset backed securities) piyasasında menkul kıymetleştirilen* parasal büyüklük 238 milyar dolara ulaşmıştır. ${ }^{9}$ Burada, menkul kıymetleştirme ile kastedilen varlığın kendisinin değil, varlığın temsil ettiği hakların ihraç edilen menkul kıymete dayanak oluşturmasıdır. ${ }^{10}$

Sekuritizasyonda temel amaç, mevcut riskin transferini sağlayarak, risk faktörünün azalmasına olanak tanımaktır. Ancak, Sekuritizasyon, uygulamada başkalarının parasıyla daha büyük kumarlar oynanmasını sağlayan bir yönteme dönüşmüştür. ${ }^{11}$

\section{Gölge Bankacılık: Kavramsal Çerçeve}

Gölge bankacılık yeni bir olgu olmamakla birlikte, özellikle küresel finans krizi konjonktüründeki rolü itibariyle öne çıkmış ve çok geçmeden finans literatüründe yerini almıştır. Gölge bankacılık üzerine son yıllarda yoğun bir literatür çalışması yapılmıştır. Finans çevreleri, gölge bankacılığını, çok farklı yönlerden ele almış ve çok farklı tanımlamalar yapmıştır. Aşağıda geniş ölçüde yer verilen bu konuya geçmeden önce, bu kurumlarla ilgili genel bir değerlendirme yapmak yararlı olacaktır.

7 Gary Gorton ve Andrew Metrick, "Securitized Banking and The Run on Repo", Journal of Financial Economics (2012), 104(3), s. 430

8 Nouriel Roubini ve Stephen Mihm, Kriz Ekonomisi: Dünya Ekonomisinin Çöküşü ve Geleceği, Çev: Işıl Tezcan, Pegasus Yayınları, İstanbul, 2011, s. 26

9 Jeremy C. Stein, "Securatization, Shadow Banking and Financial Fragility“ Deadalus, (Fall, 2010), s. 41

*Menkul kıymetleştirme, likit olmayan finansal varlıkların (mortage, otomobil kredisi ve kredi alacakları gibi) alım-satıma konu olabilir menkul kıymetlere dönüştürülme işlemidir. Bkz; Frederic S. Mishkin, The Economics of Money, Banking and Financial Markets, Sixth Edition; Addison Wesley, 2000, s.269

10 Bilge Kağan Özdemir, Finansal Küreselleşme ve Krizler, Seçkin Yayıncılık, Ankara, 2013, s. 2009

11 Aydan Kansu, Konut Balonundan Finansal Krize; ABD Mortgage Krizi, Scala Yayınc1lik, İstanbul, 2011, s.81 
Gölge bankaları, veznesi olmayan, şubesi bulunmayan, banka gibi görülen banka gibi hareket eden, banka gibi borç alıp veren, yatırım yapan ancak klasik bankalar gibi düzenlemelere tabi olmayan finans kuruluşlarıdır. ${ }^{12}$ Gölge bankacılık kavramı ilk kez 2007 yılında Mc Culley tarafından Birleşik Amerika'da Kansas City Federal Reserve Bank aracilığıyla Jackson Salonu'nda düzenlenen bir sempozyumda kullanılmıştır. ${ }^{13}$ Bununla birlikte, iki yıl önce aynı mekanda düzenlenen bir diğer sempozyumda Raguram Rajan bu kavramı tam olarak ifade etmese de, gölge bankacıllğ̆ oluşturan kırılganlıklara dikkat çekmiştir. ${ }^{14}$

Finans literatüründe gölge bankacılığı farklı türlere göre tasnifleyen, haritasını çıkaran, varlık ve fon akışını tanımlayan ilk olarak Pozser olmuştur. ${ }^{15}$ Pozser ve diğerleri, çalışmalarında gölge bankacılık kavramını kullansalar da, bu kararın çok doğru olmadığına işaret ederek konuya ihtiyatlı yaklaşmışlardır. Nitekim onlara göre, gölge bankacılığı, finansal sistemin büyük ve önemli bir parçası için küçülttücü (Pejorative) bir anlam taşımaktadır. ${ }^{16}$ Ancak, buradaki ironi de oldukça şaşırtıcıdır.

Mc Culley kaldıraçlı işlem yapan banka dışı finansal kuruluş, araç ve yapıların varlığını dikkat çekerek, gölge bankaların güvencesiz finansman bonoları aracılığı ile kendilerini fonladıklarını ( finanse ettiklerini) belirtmiştir. Mc Culley'in bu yaklaşımında yer alan kuruluş, araç ve yapılar bir bütün olarak özel amaçlı finans kuruluşları( SPV) olarak nitelendirilir. Bu varlıklar zaman zaman çok amaçlı finans kuruluşları( SPE) olarak da ifade edilmektedir. ${ }^{17}$

Gölge bankacılık, geleneksel ticari bankacılık düzenlemesine tabi olmayan dolayısıyla yasal yönden kontrol edilemeyen ve yeterince denetlenemeyen finansal faaliyetleri içen bir bankacılık türüdür. Gölge bankacılığın geleneksel bankacılık düzenlemesine tabi olmaması bu bankacılığın bizatihi 'Gölge"'(Karanlık) olarak anılmasına neden olmaktadır. ${ }^{18}$ Buna göre, geleneksel bankacılık faaliyetlerinin dışındaki tüm finansal işlemler gölge bankacılığın kapsamına girmektedir. Gölge bankacıllğın en yaygın ve kabul gören tanımı Finansal İstikrar Kurulu- Financial Stability Board(FSB) tarafından yapılmıştır. Nitekim gölge bankacılık, düzenli bankacılık sisteminin dışında kalan kuruluş ve faaliyetleri içeren kredi aracılığı olarak tanımlamıştır. ${ }^{19}$ FSB

12 Roubini, a.g.k. , s.85,87

13 Mc Culley,2007), " Teton Reflection”, Global Central Bank Focus Series, PIMCO, (August/September), s.2

14 Stijn Claessens ve diğerleri, (2012), Shadow Banking: Economics and Policy, IMF Staff Discussion Note, No:12, (December, 4) International Monetary Fund, s.5

15 Pozser ve diğerleri (2010), Shadow Banking, Federal Reserve Bank of New York Staff Report, No: 458, (July), s.4

16 Pozser ve diğerleri, a.g.e. ,s.1

17 Steven L. Schwarcz, (2011-2012), ' Regulating Shadow Banking”, Review of Banking\&Financial Law, Vol. 31, s. 620, 5 nolu dipnot

18 Laura E, Kodres, (2013), "'What is Shadow Banking?', , Finance and Development, Vol. 50, No:2, (June), s. 42

19 Financial Stability Board, Strenghtening the Oversight and Regulation Shadow Banking, (April, 2012), s.1 
bu kavramı, yaygın olması nedeniyle kullanmayı tercih etmektedir.Ancak, bazı otoriteler ya da piyasa katılımcıları piyasa temelli finansman ya da piyasa temelli kredi aracılığ

Kredi aracılığı vade, kredi ve likidite dönüştürme gibi üç fonksiyon üzerinde şekillenmektedir. Dönüştürme süreçleri genel olarak bir arada yürümektedir. Vade dönüştürme, kısa vadeli borçların, uzun vadeli varlıklara yapılan yatırımları finanse etmek için kullanılmasıdır. Likidite dönüştürme ise, likit olmayan fonlara yapılan yatırımların likit borçlarla fonlanması işlemidir. ${ }^{21}$ Buna göre, gölge bankalar, merkez bankası likiditesine ya da kamu sektör kredi garantisine başvurmadan vade, kredi ve likidite dönüşümü gerçekleştiren aracı kuruluşlar olarak ifade edilmektedir. ${ }^{22} \mathrm{Bu}$ aracılar finansman şirketleri, varlığa dayalı menkul kıymet( (asset-backed commercial paper) kondüvitleri sınırlı amaçlı finans şirketleri, yapılandırılmış yatırım amaçları, kredi hedge fonları, para piyasası yatırım fonları (money market mutual fund), menkul kıymet borç verenler( securities lenders) ve bazı kamu destekli kurumlardır. ${ }^{23}$

Gölge bankacılık alanına giren faaliyetler genel olarak menkul kıymetleştirme(securitization), repo ve para piyasası fonlarıdır. Yine bunun yanında, finansman şirketleri ve serbest fonlar gibi banka dışı finansman kuruluşlarının faaliyetleri de gölge bankacılık kapsamındadır. Gölge bankacılık kuruluşları kısa vadeli fonlar ile likit olmayan uzun vadeli yatırım yaparak vade ve likidite dönüştürme faaliyetinde bulunmaktadır. ${ }^{24}$ Yukarıda da belirtildiği gibi gölge bankaları kaldıraçlı işlemler gerçekleştirmekte ve risk transferi yapabilmektedir.

Ancak, gölge bankacılığının yukarıdaki tanımı dar anlamda kabul edilmekte, yeterince kapsamlı olmadığı gerekçesiyle daha geniş bir tanıma ihtiyaç bulunduğuna işaret edilmektedir. Nitekim Schwarcz, gölge bankacılığının bu bankaların yaptıkları faaliyetler dikkate alınarak bir tanımın yapılmasının daha doğru olacağını öne sürmektedir. Schwarcz, geleneksel bankacılık dışında tüm faaliyetlerin gerçekleştirilmesini gölge bankacılık olarak kabul etmektedir. Buna göre, finansal ürün ve hizmetlerin tedariki gölge bankacılık kapsamındadır. Gölge bankaları ürün ve hizmetleri finansal piyasalar aracılığıyla sağladığından, Schwarcz'ın tanımı içerinde finansal piyasalar önemli bir yer tutmaktadır. Dolayısıyla, O’na göre, gölge bankacılık, sadece finansal ürün ve hizmetler bu bankalar tarafından tedarik edildiği için değil, aynı zamanda bu ürün ve hizmetlerin tedarikinde finansal piyasalar kullanıldığg için de geniş bir manada ele alınmalıdır. ${ }^{25}$

Gölge bankacılığın tanımına ilişkin benzeri bir yaklaşım Claessens ve Ratnovski tarafından geliştirilmiştir. Onlara göre, gölge bankacılığg faaliyet temelinde ele alınmalı ve özel ya da kamu desteği gerektiren geleneksel bankacılık dışındaki

\footnotetext{
20 Financial Stability Board a.g.r., s.1

21 Pozser ve diğerleri,a.g.e., s.8

22 a.g.e., s.11, 7 nolu dipnot

23 Schwarcz, a.g.m., s.621

24 TCMB, Finansal İstikrar Raporu, (Kasım, 2014), s:19, s. 100

25 Schwarcz, a.g.m., s.622
} 
tüm finansal faaliyetler olarak tanımlanmalıdır. ${ }^{26}$ Burada finansal faaliyet kapsamı oldukça geniş tutulmuştur. Çünkü gelecekte bir kaç finansal faaliyet gölge bankac1lığının konusunu oluşturabilir. Kaldı ki, finansal faaliyetler ülkeden ülkeye farklılık göstermektedir. Nitekim, Avrupa'da sigorta şirketleri tarafından kredi verilmesi gölge bankacılık olarak kabul edilmektedir. ${ }^{27}$ Çin Halk Cumhuriyeti'nde bankalar tarafından arz edilen servet yönetim ürünleri (wealth management products) ve Hindistan'da banka destekli (bank- affilates) finans şirketleri tarafından kredi verilmesi de gölge bankacılık olarak kabul edilmektedir. Bu nedenle de, tüm bu finansal faaliyetler gölge bankacılığının konusunu oluşturabilir.

Öte yandan, gölge bankacılığını faaliyet çerçevesinde ele alarak tanımlayan bir diğer çalışmada, gölge bankacılığı, mevduat toplamaksızın ve kredi garantisi bulunmaksızın yapılan kredi aracılığg olarak ifade edilmiştir. Bu tanıma göre, gölge bankaları yine geleneksel bankaların dışında kalan ancak sahip oldukları fonları, fon talep edenlere kanalize eden uzmanlaşmış finans kuruluşları olarak ele alınmıştır. ${ }^{28}$

\section{Gölge Bankacılığın Boyutları}

Gölge bankacılık yukarıda da değinildiği üzere yeni bir olgu değildir. Bu tür bankacılık 1970'li yılların başından itibaren varlığını hissettirmiş özellikle de 2008 küresel kriz koşullarında hızla büyümüştür. Gölge bankacılık sisteminin doğuşu 1970'li yıllarda para piyasası fonlarının gelişmesi ile birlikte olmuştur. $\mathrm{O}$ yıllarda bu fonlar banka mevduat hesapları gibi fonksiyon gören, ancak bankalar gibi düzenlenmemiş kuruluşlardır. Bu fonların büyüklüğü 1980'li yılların başında 100 milyar doların biraz altındayken, 2000 yılında 2 trilyon dolar düzeyine çıkmıştır. ${ }^{29}$ Finansal İstikrar Kurulu( Financial Stability Board), gölge bankacılığın büyüklüğünün ölçülmesinde banka dışı finansal aracılığ 1 diğer bir değişle diğer finansal kuruluşları dikkate almaktadır. Finansal İstikrar Kurulu'nun bu tanımına göre, diğer finansal kuruluşlar; sigorta şirketleri, emeklilik fonları ve kamu finansal kuruluşları dışında kalan ve kredi aracılık faaliyetinde bulunan finansal aracıları kapsamaktadır. ${ }^{30}$

Gölge bankacılığın büyüklüğünün ölçülmesi, bu tür bankacılığın tanımlanma biçimiyle yakından bağlantılıdır. Bilindiği gibi, Finansal İstikrar Kurulu, gölge bankacılığı, düzenli bankacılık sistemi dışında kalmış kuruluş ve faaliyetleri içeren kredi aracılığ 1 olarak tanımlamaktadır. Bu, geniş bir tanımlamadır. Bu tanımdan yola çıkıldığında, gölge bankacılığın büyüklüğü de farklı olmaktadır. Finansal İstikrar Ku-

26 Stijn Claessens ve Lev Ratnovski, (2014), What is Shadow Banking? , IMF Working Paper, No. 14/25, International Monetary Fund, s.4

27

28 Tobias Adrian ve Adam B. Ashcraft, (2012), Shadow Banking: A Review of the Literature, Federal Reserve Bank of New York Staff Report, No:580, s.2

29 Thorvald Grung Moe, Shadow Banking and the Limits of Central Bank Liquidity Support: How to Achieve a Better Balance between Global and Official Liquidity, Working Paper, No:712, Levy Economics Institute of Bard College, 2012, s.37

30

FBS.,(2014), a.g.r., s.14 
rulu 2014 yılı raporunda gölge bankacılığının tanımını daraltma yoluna gitmiştir. Dar anlamda gölge bankacılık, bu kez banka dışı kredi aracılığının alt kümleri üzerine odaklanmıştır. Böylece, sistematik riskler de dikkate alınmış olmaktadır. Burada dar ölçme yönteminin kullanılmasıyla, kredi aracı sisteminin parçası olmayan kuruluşlar ayıklanmaktadır.

Finansal İstikrar Kurulu'nun, diğer finansal aracıların(kuruluşların) varlıkları dikkate alınarak yaptığı hesaplamaya göre, gölge bankacılığın dünya ölçeğindeki büyüklüğü 2013 yılı sonu itibariyle 5 trilyon dolarlık artış sonucu 75 trilyon dolara ulaşmıştır. ${ }^{31}$ Gölge bankacılığın varlık büyükklüğü toplam finansal varlıkların yaklaşık yüzde 25 'ini oluşturmakta ve küresel bankacılık sisteminin varlıklarının yaklaşık yarısına baliğ olmaktadır.

Yine aynı kaynağa göre, gölge bankacılık varlıklarının ülke milli gelirlerine oranı da hızla artmaktadır. Nitekim 2011 yılında küresel finans kriz sonrası en düşük seviye olan yüzde 112 'den nisbi bir artışla yüzde 120 'ye ulaşmış bulunmaktadır. ${ }^{32}$ Gerçekten de, artış yönündeki bu gelişme, nisbi de olsa, gölge bankacılığın büyüme eğilimini sürdürdüğünü ortaya koymaktadır.

Finansal İstikrar Kurulu'nun verilerine göre, halen gölge bankacılığı en ağırlıklı olduğu coğrafya Birleşik Amerika ve Euro bölgesidir. Bu ülkelerin varlıklarının büyüklüğü 2013 yılı itibariyle 25 trilyonun biraz üzerinde olup, küresel gölge bankacılık varlıkları toplamının üçte birini oluşturmaktadır. İngiltere küresel gölge bankacılığın üçüncü büyük ülkesidir. 2013 yılı sonu itibariyle İngiltere gölge bankacılığının varlıkları toplam 9.3 trilyon dolara ulaşmıştır. Buna göre, Birleşik Amerika, İngiltere ve Euro bölgesinin bir bütün olarak varlıklarının toplamı küresel gölge bankacılık varlıklarının yüzde 80'ini oluşturmaktadır. Gelişmekte olan ülkeler arasında ise en büyük artış Çin Halk Cumhuriyeti'nde görülmektedir. Gelişmekte olan ülkelerde 2012 yılı verileri dikkate alındığında gölge bankacılığının payı azalma göstermekle birlikte, S.Arabistan, Arjantin ve Şili'de net döviz kuru etkileri nedeniyle bir artı̧̧ sözkonusudur. Özellikle Çin ve Arjantin gelişmekte olan ülkeler arasında gölge bankacılık varlıkları en hızlı büyüyen ülkeler olarak dikkati çekmektedir.

Küresel gölge bankacılığın alt-sektör itibariyle yüzde dağılımı da farklılık göstermektedir. Aşağıdaki diyagramdan da görüleceği gibi, 2013 yılı baz alındığında toplam olarak 24 trilyon dolarlık büyüklüğe sahip olan gölge bankacılık alt-sektörleri arasında en büyük pay yüzde 38 ile Diğer Yatırım Fonlarına (Other Investment Funds) aittir. Bu oran 2012 yılında yüzde 34 düzeyindedir. 


\title{
Gölge Bankacılık Kompozisyonu (Yüzde)
}

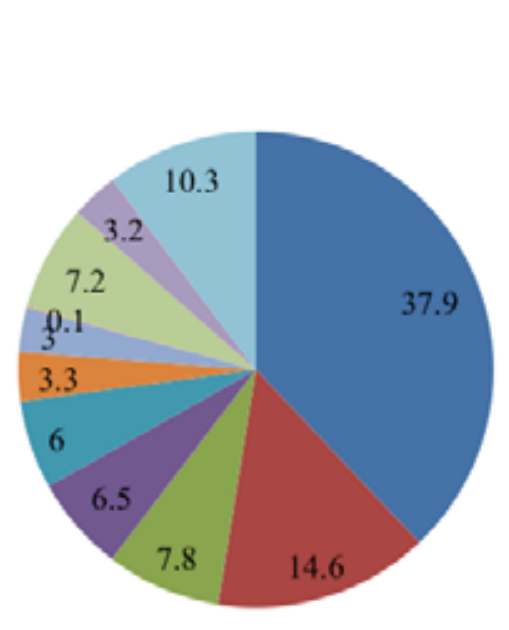

\author{
- Diğer Yatırım \\ Fonları \\ - Arac1 Kurumlar \\ = Yapılandırılmış \\ Finansal Araçlar \\ - Finansman \\ Şirketleri \\ "Para Piyasası \\ Fonları \\ =Yatırım \\ Ortaklıkları \\ $=\mathrm{GYO}$
}

Kaynak: FSB, a.g.r., s. 14

Diğer yatırım fonları genel olarak Hisse Senedi Yatırım Fonları, Sabit Getirili Fonlar ve Diğer Fonlardan ibarettir. Diğer Yatırım Fonlarının yüzde 15'i ile Aracı Kuruluşlar ve yüzde 8 ile yapılandırılmış Finansal Araçlar izlemektedir.

\section{Geleneksel Bankacılık ile Gölge Bankacılık Karşılaştırması}

Gerek yasal gerekse uygulama biçimi yönünden heriki bankacılık arasında hem benzerlikler hem de oldukça büyük farklılıklar sözkonusudur. Bu benzerlikleri ve farklılıkları aşağıda belirtildiği şekilde özetlemek mümkündür: ${ }^{33}$

- Geleneksel bankacılık sisteminde olduğu gibi gölge bankacılık sisteminin de temel işlevi fon fazlası olanlar ile fon açığı olanlar arasında aracılık işlevini yerine getirmektedir. Ancak, geleneksel bankacılık sisteminde fonların temel kaynağı mevduatlarken, gölge bankacılık sistemi mevduat kabul etmediği gibi, burada fonların kaynağını repo oluşturur. Bu farklılık, aynı zamanda iki sisteme yönelik olarak gerçekleşen hücumların farklı olmasına yol açmaktadır. Geleneksel bankacılık sisteminde banka hücumları (bank run) mevduatı çekmek amacıyla yapılırken, gölge bankacilık sisteminde hücumların konusu repo ve benzeri ürünlerdir. Bu nedenle, gölge bankacılığın 2008 mortgage krizindeki rolüne dikkat çekmek amacıyla, bu kriz 'repoya hücum"'(run to repo) olarak nitelendirilmiştir. ${ }^{34}$

- Gerek geleneksel bankacılık sistemi, gerekse gölge bankacılık sistemi kredilere aracılık etmektedir. Ancak, geleneksel bankacılık sisteminde kredi aracılık süreci tek bir çatı altında gerçekleştirilirken, gölge bankacılık sektöründe bu süreç bir dizi

\footnotetext{
33 Bilge Kağan Özdemir, a.g.k., s.224

34 Garry Gorton ve Andrew Metrick, a.g.m., s.425
} 
farklı kuruluşun işin içine girmesiyle yürümektedir. Bu nedenle, gölge bankacılık sisteminin operasyonları daha karışık bir yapı içerir.

- Bu iki finansal sistem arasında bir diğer farklılık ise denetleme ve düzenleme mekanizmalarıyla ilgili olarak ortaya çıkmaktadır. Geleneksel bankacılık sistemi kesin kurallarla denetleme ve düzenlemeye tabi iken, gölge bankacılık sistemi nerdeyse denetleme ve düzenlemelerin bütünüyle dışındadır. Bu farka bağlı olarak, geleneksel banka merkez bankası kaynaklarına başvurabildikleri gibi, mevduat sigortası uygulamasından da yararlanırlar. Gölge bankacılık sistemi ise, piyasaların panik yaşadığı bir ekonomik ortamda kendilerini korumaya alacak bir güvenlik ağı bulunmamaktadır.

- Geleneksel bankalar kullandırttıkları kredileri vadesi dolana kadar bilançolarında tutarlar. Gölge bankacılık ise menkul kıymetleştirme (securatization) sayesinde yaratılan krediler dağıtılır.

Gölge bankacılık üzerine yaptıkları yetkin ve analitik çalışmalarıyla tanınan Gorton ve Metrick geleneksel ve gölge bankacılık arasındaki temel farklılıklar aşağıdaki tabloda görüldüŭgu gibi özetlemişlerdir.

\section{Geleneksel Bankacılık Sistemi ile Gölge Bankacılık Sistemi Arasındaki Farklar}

\begin{tabular}{|c|c|}
\hline Geleneksel Bankacılık & $\begin{array}{l}\text { Menkul Kıymetleştirmeye Yönelik Bankacı- } \\
\text { lık (Gölge Bankacılık) }\end{array}$ \\
\hline $\begin{array}{l}\text { Rezervler: } \\
\text { - Minimum düzeyler, düzenleme oto- } \\
\text { riteleri tarafından belirlenmektedir. } \\
\text { - Sermaye açı̆ı halinde merkez ban- } \\
\text { kasından borçlanılabilir. }\end{array}$ & $\begin{array}{l}\text { - Minimum düzeyler taraflar tarafın- } \\
\text { dan belirlenmektedir. } \\
\text { - Merkez bankasından borç alınamaz. }\end{array}$ \\
\hline $\begin{array}{l}\text { Mevduat Sigortası: } \\
\text { - Devlet tarafından garanti altına alın- } \\
\text { mıştır. }\end{array}$ & $\begin{array}{l}\text { Teminat: } \\
\text { - Nakit, hazine bonosu, menkul kıy- } \\
\text { metler, krediler ya da menkul kı- } \\
\text { metleştirilmiş bonolar }\end{array}$ \\
\hline $\begin{array}{l}\text { Mevduat Faiz Oranı: } \\
\text { - Rezervler düşük düzeyde kaldığın- } \\
\text { da, mevduatlarda artış sağlamak için } \\
\text { faiz oranları artırılabilir. }\end{array}$ & $\begin{array}{l}\text { Repo Oranları: } \\
\text { - Fonlar düşük düzeydeyken, tarafları } \\
\text { çekmek için repo oranları artırılabi- } \\
\text { lir. }\end{array}$ \\
\hline Krediler, bilançoda yer almaktadır. & $\begin{array}{l}\text { Menkul Kıymetleştirilmiş Krediler: } \\
\text { - Bazı menkul kıymetleştirilmiş bono- } \\
\text { lar bilançoda tutulabilir ve teminat } \\
\text { olarak kullanılabilir. }\end{array}$ \\
\hline
\end{tabular}

Kaynak: Garry Gorton ve Andrew Metrick, a.g.m., s. 428

Tablodan da görüleceği üzere, gölge bankacılığın ana fonlama kaynağı repo piyasası, risk marjı ve bilanço dışı faaliyetler oluşturmaktadır. Yine, bir diğer önem- 
li fonlama kaynağı da menkul kıymetleştirilmiş varlıklardır. Gerçekten de kredilerin yatırımcılara paketlenmesi ve satılması sürecini ifade eden menkul kıymetleştirme, gölge bankacıllğı için yeni ve önemli bir fonlama kaynağı olmuştur ${ }^{35}$. Öte yandan, geleneksel bankacılık sisteminde bazı teminat amaçlı menkul kıymetleştirilmiş bonolar bilançoda yer almasına karşılık, gölge bankacılıkta bilançoda ancak bazı teminat amaçlı menkul kıymetleştirilmiş bonolar yer bulmaktadır. Tablodan da izlenebildiği gibi, her iki bankacılık arasında en temel ayrılık mevduat sigortasında ortaya çımaktadır. Bilindiği gibi, mevduat sigortası, devletin olası bir ödeme sorununun yaşanması durumunda, mevduat sahiplerine (mudilere) yaptığı bir taahhüttuir. Buna göre, geleneksel bankacılıkta mevduat sigortası devlet tarafından tam ya da kısmi bir güvenceye alınmış iken, gölge bankacılıkta bu bankacılığın doğası gereği bir devlet garantisi söz konusu değildir.

\section{Gölge Bankacılığın Kredi Aracılığı Fonksiyonu}

Gölge bankacılığı, kredi aracılığı yapan bir bankacılık türüdür. Diğer bir deyişle, gölge bankaları finansal aracılık kurumlarıdır. Gölge bankaları, topladıkları mevduatları uzun dönemli krediler olarak kredi talep edenlere plasman yaparlar. Tasarruf sahipleri ve kredi talep edenler arasındaki nakit akışının riskini dönüştüren bu faaliyet finans literatüründe finansal aracılık olarak tanımlanır. ${ }^{36}$ Finansal aracılı̆̆ın ana amacı kredi sağlamaktır. Kredi sağlamada, hem ticari bankalar hem de gölge bankacılık sistemi içindeki kuruluşlar kredi riskini kabul etmek ve onu yönetmek zorundadirlar.

Aşağıdaki şekilde geleneksel bankacılık ile gölge bankacılı̆̆a ilişkin finansal aracılık kanallarının işleyişi gösterilmiştir. Sürecin işleyişiyle kişilerin, hükümetlerin ve şirketlerin ekonomik faaliyetlerini sürdürmelerini sağlayacak kısa vadeli tasarruflar uzun vadeli sermaye kaynaklarına dönüşmektedir. Ticari bankalar ya da gölge bankacılık piyasalarda faaliyette bulunan ticari bankalara bağlı şirketler geleneksel bankacılık işlevini, diğer bir deyişle kredi aracılığını yerine getirmektedir. Böylece heriki bankacılık sistemi de aynı finansal işlevlerde birlikte yer almaktadır. Kaldı ki, kendileri yeni finansal risk türleriyle karşı karşıya kalmalarına karşın, yeni gelir kaynağı sağlamak üzere gölge bankacılık alanına girmekten kaçınmamışlardır. ${ }^{37}$

35 Tobias Adrian ve Hyun Song Shin, The Shadow Banking System: Implications for Financial Regulation, Federal Reserve Bank of New York Staff Report; No.382, (July ,2009), s. 11

36 Financial Crisis Inquiry Commission, (FCIC), Shadow Banking and the Financial Crisis, Preliminary Staff Report, 2010, şekil-2, s.10

37

FCIC, s. 10 


\section{Şekil 1: Bankalar ve Piyasalar Kanalıyla Finansal Aracılık}

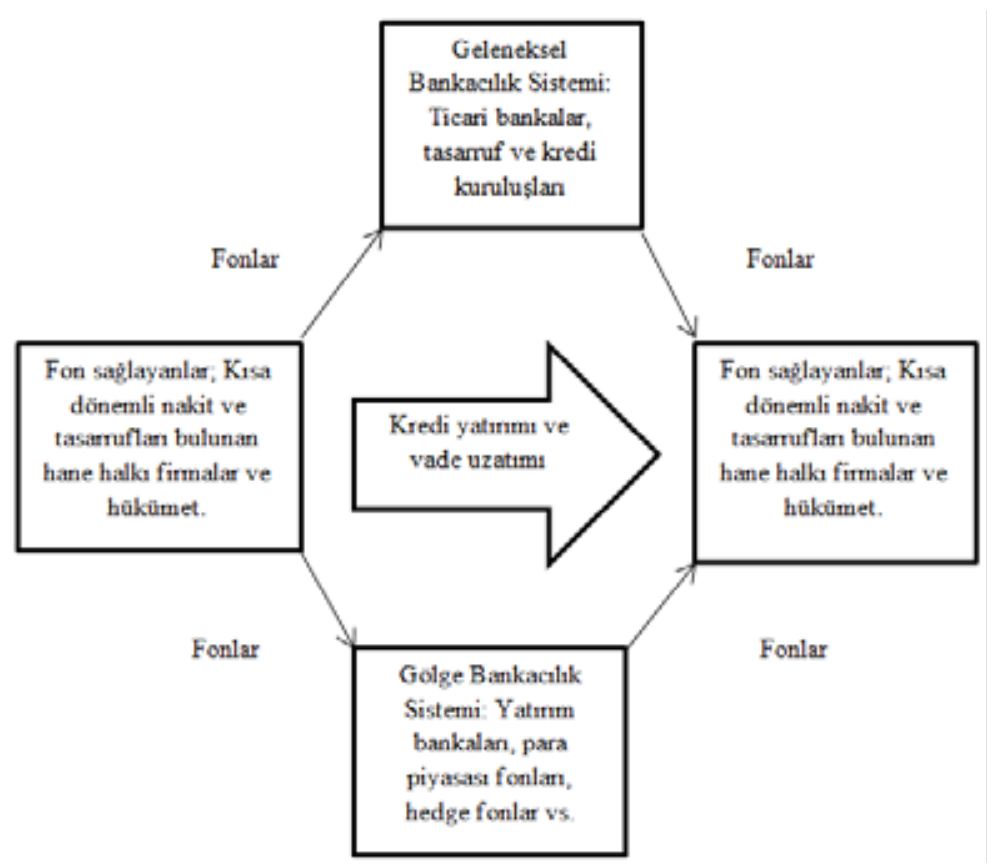

Kaynak: Financial Crisis Inquiry Commission, FCIC. (2010). Shadow Banking and the Financial Crisis, Preliminary Staff Report, Şekil-2, s.10

Şurası açıktır ki, gölge bankacılık kurumlarının birçoğu finansal strese karşı aşırı ölçüde duyarlı olup, kırılgan bir yapıya sahiptirler. Herşeyden önce, gölge bankaları çok yüksek kaldıraçlı (high leveraged) işlemler yapmaktadır. Bilindiği gibi, yüksek kaldıraç belli bir özsermaye miktarıyla yatırım yapan firmalara ve özsermaye sahiplerine, aynı özsermaye miktarı ile yüksek kârlılık potansiyeli sağlayan bir finansal işlemdir. Bu mekanizma yatırımcısına yatırdığı teminatın üzerinde işlem yapabilme olanağı sağlamaktadır. ${ }^{38}$ Ancak, bu mekanizma belli riskleri de bünyesinde barındırır. Nitekim, çok yüksek kaldıraçla çalışan (dolayısıyla daha düşük sermayeyle) fïrmalar muhtemelen beklenmedik kayıplarla ve borcunu ödeyemez duruma düşme tehlikesiyle karşı karşıya kalabilmektedir. ${ }^{39}$

\section{Gölge Bankacılığın Avantajları ve Riskleri}

Banka dışı kanallar aracılığıyla kredi aracılığı fonksiyonunu yerine getiriyor olması, gölge bankacılığının önemli bir avantajı olarak kabul edilir. Zira, gölge bankacılığı bu yolla finansal derinleşmeyi artırıcı etki yapmaktadır. Öte yandan, piyasa

38 Doruk, a.g.m., s.537

39 FCIC, a.g.r., s. 15 
aktörlerine ve şirketlere alternatif bir fonlama ve likidite kaynağı görevini yapması da, bu tür bankalar için olumlu bir faktördür. ${ }^{40}$ Böylece, gölge bankacıllığ reel ekonominin finansmanında etkin bir rol oynamaktadır.

Üstelik, gölge bankalarının teknolojik gelişmeyi yakından izleyerek faaliyetlerinde yüksek teknolojiyi kullanmaları, bu bankacılık türünün hızla büyümesinde de etken olduğu kabul edilmektedir. Gerçekten de, finansal yenilikler ve teknolojik gelişmeler geleneksel bankacılık sisteminin dışında hızlı bir kredi artışına yol açmıştır. Sheng'in de belirttiği gibi, finansal mühendislik, sistem dişında kredinin inanılmaz ölçüde artışın ana mecrasını oluşturmuştur. ${ }^{41}$ Gölge bankalar geleneksel bankacıllı̆̆ oranla daha yenilikçi finansal ürünler kullanabilmektedir. Geleneksel bankaların finansal ürünler için yatırımcı talebine cevap verme kapasitesi sınırlıdır. Buna karşılık, teknoloji, hedge fon gibi banka dışı finansal proje katılımcılarına, finansal ürünleri daha hızla ve daha düşük maliyetle karşılamada geleneksel bankalara oranla rekabet avantajı sağlamaktadır. ${ }^{42}$ Gerçekten de, Langvoort'un da belirttiği gibi, bankacılıkta teknolojik yenilik, rekabetin, geleneksel olarak kısa vadeli borçlanma araçlarının yapılandırılmasında uzmanlaşmış bankalardan gölge bankacılığa doğru kaymasına neden olmuştur. ${ }^{43}$

Bankacılık sektörü likidite, sermaye ve kaldıraç düzenlemelerine tabi olduğundan kredi aracılık faaliyetleri kısıtlanabilmektedir. Buna karşılık, gölge bankaları, yeni finansman olanakları sunduğundan ekonomin kredi ihtiyacını karşılamada aktif bir rol oynayabilmekte ve finansal sistemi daha etkin bir konuma getirmektedir. ${ }^{44}$ Gerçekten de, gölge bankacıllı̆ın etkinlik, uzmanlaşma, çeşitlendirme, risk azaltma, esneklik gibi sahip olduğu özelliklerinin yanısıra özellikle büyük ölçüde fonlama ve likidite sağlama, finansal sistemin güvenliğine ve istikrarına önemli katkı olarak kabul edilmektedir. ${ }^{45}$

Ayrıca, gölge bankacılığında risk transferinin mümkün olabilmesi finansal istikrar için de olumlu bir katkı niteliğindedir. Dahası, risklerin geleneksel bankacılık sistemi dışında transferi yatırımcılar için de önemli bir avantaj sağlamaktadır. Bu durumda, yatırımcılar üzerinde yatırım yapma isteğini uyandırabilmektedir. Bunun gerçekleşmesi durumunda da, piyasa likiditesinin artması sözkonusu olmaktadır. ${ }^{46}$

40 Marianne Ojo, Financial Stability, New Macro prudential arrangements and shadow banking: regulatory arbitrage and stringent Basel III regulations, Munich Personal RePEC Arcihive, MPRA Paper, 2011, No.31319 s.n.y.

41 Anderw Sheng, Central Banking in a Era of Quantitatise Easin, Working Paper, No. 684, NY, Levy Economics Instute of Bard College, 2011, s.10

42 Schwarcz, a.g.r., s.625-626

43 Donald C., Langvoort, 'Global Securities Regulation after the Financial Crisis', Journal of International Economic Law, 13/3, 2010, s.803

44 TCMB, a.g.r., s. 104

45 Institute of International Finance, "Shadow Banking": A Forward Looking Framework For Effective Policy, ( June, 2012), s.5

TCMB, a.g.r., s.104 
Daha önce de belirtildiği gibi, gölge bankacılığı aynı geleneksel bankacılık gibi vade, kredi ve likidite dönüşümü gerçekleştirmektedir. Ancak, bu fonksiyonları gerçekleştiriyor olması bu bankacılığı kırılgan bir hale getirmektedir. Özellikle, vade dönüştürme piyasalara likidite sağlamakta birlikte, aynı zamanda aracılık yapan kuruluşların vadeden vadeye geçiş (rollover) ve durasyon riskleriyle karşı karşıya kalmalarına neden olmaktadır. ${ }^{47}$

Doğası gereği bu bankacılık için sistematik riskler olağan olup, bizatihi kendisi risklerin kaynağıdır. Nitekim, 2008 finansal krizi, gölge bankacılığın neden olduğu sistematik riskleri açık bir biçimde ortaya koymuştur. ${ }^{48}$ Gölge bankacılığın kaynağı olduğu riskler; genel olarak sermaye ve menkul kıymet piyasaları üzerinden faaliyetlerin görülmesi ve bu piyasaların risklerine açık bulunması ya da bu piyasalar için risk oluşturacak varlık alım-satım yoğunluğu sonucunda balon oluşmasına neden olması biçiminde özetlenebilir. ${ }^{49}$ Nitekim, gölge bankacılığı 2008 finans krizinde resmi ve ticari emlak piyasasında varlık balonlarının şişmesinde önemli rol oynamıştır. Üstelik, gölge bankacılığı uzun dönemli sermaye ihtiyacını kısa dönemli olarak fonlamasına karşın, likidite sağlamada kesinti riski de oluşturabilir. Diğer bir deyişle bu fonlamayı uzun süre sürdüremeyebilir. Bu nedenle de, gölge bankacılığının kısa vadeli fonlama işlevi sadece gölge bankacılığının sorunu değil, aynı zamanda finansal sistemin sorunudur. 50

Gerçekten de, bölge bankacılığı aynen geleneksel bankacılık gibi vade uyumsuzluğu riskinin yanında, likidite riskiyle karşı karşıya kalması nedeniyle, ciddi anlamda krizlerin kaynağı ya da en azından tetikleyicisi olabilmektedir. Özellikle stres dönemlerinde hücumlara uğrayabilmektedir. ${ }^{51}$

Burada hücumların yönü doğrudan repo piyasası ya da borçlanma senedi piyasalarıdır. Ne var ki, gölge bankacılık kuruluşları yasal yönden bir teminat güvencesi altında olmayıp ihtiyati düzenlemelerin dışında kaldıklarından, risklerin bu kuruluşlar üzerindeki etkisi çok daha büyük maliyetler yaratabilmektedir. ${ }^{52}$

Öte yandan, gölge bankaları kaldıraçlı işlemler yaptıklarından, yüksek kaldıraç finansal piyasalarda kırılganlığı artırarak sistematik risklere yol açmaktadır. Gölge bankacılığı, düzenlemeye ve denetlemeye bağlı sınırlamalara maruz kalmaksızın, defaten ihraç yolu ile yüksek kaldıraç yaratarak teminatlı fonlama kanalını kullanır. ${ }^{53}$ Ancak, bu durum kaldıraç oranlarının artmasına neden olmaktadır. Nitekim, istikrar

47 Tobias Adrian ve Adam B. Ashcraft, Shadow Banking Regulation, Federal Reserve Bank of New York Staff Reports, No.559, (April, 2012), s.5

48 Stijin Claessens, a.g.m., s.6

49 Yusuf Dinç, 2015, Gölge Bankacılıktan Repolar Bankacılığa Geçiş, Özel Finans Kurumları Örneği, Basılmamış Doktora Tezi, M.Ü. Bankacılık ve Sigortacılık Enstitüsü, s.110

50 Schwarcz, a.g.r., s.625

51 Schwarcz, a.g.r., s.625

52 TCMB, a.g.r., s.104

53 Dinç, a.g.e., 112 
dönemlerinde kaldıraçlı işlemler nedeniyle varlık fiyatları yükselmekte, teminat gösterilen varlıklara uygulanan iskonto oranları düşmekte ve kredi büyümesi hızlanmaktadır. Buna karşılık, stres dönemlerinde teminatların değeri düşmekte, iskonto oranları artmakta ve finansal stres daha da derinleşmektedir. ${ }^{54}$

\section{Gölge Bankacılığın Düzenlemesi}

Gölge bankacıllı̆ııın, 2008 küresel finansal krizinde yarattığı büyük tahribat üzerine, bu bankacılığın denetimi ve düzenlenmesi, diğer bir deyişle disipline edilmesi kaçınılmaz bir ihtiyaç olarak kendisini göstermektedir. Burada temel amaç; aracılık faaliyetini engellemeden bu faaliyetlerinden kaynaklanan finansal istikrar risklerinin azaltılmasıdır. ${ }^{55}$

Finansal istikrar kurulu (FSB), 2011 yılındaki G 20 liderleri zirvesinde alınan kararla, izleme ve geliştirme amaçlı raporlar hazırlamakla görevlendirilmiştir. Finansal istikrar kurulu gölge bankacılığın taşıdığı sistematik riskleri azaltmak amacıyla düzenleme çalışmalarını beş ana konu üzerinde yoğunlaştırmıştır. ${ }^{56}$

- Düzenli bankacılık sistemi ile gölge bankacılık arasında bulaşma etkisini azaltmak;

- Para piyasası fonlarından kaçış riskini azaltmak;

- Menkul kıymetleştirme (secutitization) işlemlerinin şeffaflaştırılması ve standartlaştırılması

- Repo ve diğer menkul kıymet ödünç verme işlemlerinden kaynaklanan riskleri azaltmak;

- Diğer gölge bankacılık kuruluşlarının ve faaliyetlerinin neden olduğu sistematik riskleri saptamak ve azaltmak

Aşağıda bu risklerden önemli görülen ikisine yer verilmişstir.

\section{Bulaşma Etkisini Azaltılması}

2008 krizinde görüldüğü ve yaşandığı gibi, gölge bankacılığının doğası gereği taşıdığı riskler nedeniyle bankacılık sektörü üzeninde yarattığı olumsuzluklar ve bulaşma etkisinin*(contagine) önüne geçebilmek amacıyla, Basel Bankacılık Denetim

54 TCMB, a.g.r., s.104

55 TCMB, a.g.r., s.105

56 Financial Stability Board, Regulatory framework for haircuts on non-centrally cleared securities financing transactions, (14 October, 2014), s.i

* Bulaşma etkisinin, finans literatüründe dar ve geniş olmak üzere çok çeşitli tanımları bulunmaktadır. Dar anlamda bulaşma etkisi, bir finansal sorunun bir kurum bir piyasa ya da sisteminden diğerlerine yayılması; geniş anlamda ise, birçok kurum ya da piyasayı aynı anda olumsuz yönde etkileyen büyük sistematik şokları ifade etmektedir. Bkz; Oliver De Bandt ve Philipp Hartman, "Systemic Risk: A Survey", European Central Bank Working Paper Series, No:35, (November, 2000), s. 55 
Otoritesi (Basel Committee on Banking Supervision)-BCBS- tarafından yeni düzenlemeye gidilmiştir. Bankaların yaratabileceği kredi hacmine sınırlama getirilmiştir. Buna göre, bankanın özkaynaklarının yüzde 10'una eşit ya da üzerindeki miktar büyük kredi olarak tanımlanmıştır. Bir bankanın karşı tarafa ya da karşı tarafla bağlantılı bir gruba vereceği büyük kredilerin büyüklüğü bankanın mevcut ana sermayesinin yüzde 25 'inden büyük olmamalıdır. Ancak, bu oran küresel sistematik öneme sahip bankalar (global systemically important bank)-G-SIB- için daha da sıkıştırılmış ve yüzde 15 'le sınırlandırılmıştır. ${ }^{57} \mathrm{Bu}$ düzenlemenin temel amacı, bankaların, karşı tarafın beklenmedik şekilde temerrüde (ödeme güçlüğüne) düşmesi durumunda ortaya çıkabilecek büyük kayıplardan korunmasıdır.

\section{Para Piyasası Fonlarından Kaçıs Riskini Azaltmak}

Bilindiği gibi, 2008 küresel kriz süresince para piyasası fonlarından kaçış (çıkış), bu fonların krizle sistematik bağını ortaya koymuştur. Para piyasası fonları, krizin doğuran nedeni olmamakla birlikte, bu fonların performansının krizin yayılmasına hatta derinleşmesine yol açtığı açıktır. Para piyasası fonları, genel olarak, sermayeyi korumayı ve günlük likidite değerlemeyi amaçlayan yatırım fonlarıdır. Buna göre, para piyasası fonları önemli bir kredi ve likidite kaynağıdır. Bu fonlar halen finans piyasalarında önemli bir büyüklüğe sahiptir. Nitekim, 2011'in ilk çeyreği itibariyle para piyasası fonlarının büyüklüğü 4.7 trilyon dolardır. Birleşik Amerika ve Avrupa küresel para piyasası fonları toplamının yüzde 90'ını oluşturmaktadır. ${ }^{58}$

Para piyasası fonları kısa vadeli borçlanma araçlarına yatırım yapmakta ve sabit net varlık değeri üzerinden işlem görmektedir. Olumsuz piyasa koşullarında bu fonların yatırım yaptığı menkul kıymetlerin değeri düşerken fonun değerinin düşmesine izin verilmemektedir. Bu durum, fonlara yatırım yapan yatırımcılarda fondan çıkışta geç kalan yatırımcıların parasını tahsil edemeyeceği algısını doğurmaktadır. Dolayısıyla, yatırımlarını para piyasası fonlarında değerlendiren yatırımcılar bu fonlardan aniden çıkabilmektedir. ${ }^{59}$ Bu çıkış para piyasasında domino etkisi yaratabilmektedir. Çünkü, bu fondan çıkış diğer fonlar üzerinde de çıkışa (kaçışa) yolaçabilmekte, dolayısıyla bu durum tüm finansal sistemi olumsuz yönde etkileyebilmektedir. ${ }^{60}$

$\mathrm{Bu}$ nedenle, para piyasası fonlarının neden olabileceği riskleri azaltmak amacıyla Uluslararası Menkul Kıymet Komisyonları Örgütü (IOSCO) tarafından 2012 yılı Ekim ayından politika önerilerini içeren bir rapor yayımlanmıştır. ${ }^{61} 19$ maddeyi içeren bu politika temelinde en dikkati çeken öneriler 7'nci, 8'nci ve 10'cu önerilerdir. Bunlara göre, para piyasası fonlarının minimum miktarda likit varlık bulundurması, periyodik olarak stres testlerinin yapılması ve bu fonların sabit net varlık değeri yerine, değişken net varlık değeri üzerinden işlem görmesi öngörülmektedir.

57 Bank for International Settlements, (BIS), Supervisory farmework for measuring and controlling large exposures, (April, 2014), s. 4

58 International Organization of Securities Commissions, (IOSCO), (October, 2012), s.14

59 TCMB, a.g.r., s.107

60 IOSCO, a.g.r., s.7

61 a.g.r., s. 19 


\section{Sonuç}

Görüldüğü gibi, gölge bankacılık, küresel finansal krizin başlamasında ve yaygınlaşmasında doğrudan rol oynamıştır. Reel ekonominin finansmanı, finansal derinleşme, vade ve likit dönüşümü, risk paylaşımı ve daha yenilikçi bir finansal sistem yaratma gibi avantajları olsa da, gölge bankacılık 2007 krizi koşullarında yasal boşluktan yararlanarak kontrol ve denetim dışı kalmıştır. Etki alanı sadece Birleşik Amerika ile sınırlı kalmamış, küresel ölçekte ve geniş bir coğrafyada varlık bulmuştur.

Yarattığı ve yol açtı̆̆ı olumsuzluklar nedeniyle, bu bankacılığın, özellikle yasal yönden düzenlemelere tabi tutulması zorunluluk olmuştur. Nitekim, gölge bankacılık özellikle 2011 yılından itibaren uluslararası finansal sistemi düzenleyen ve yönlendiren kuruluşlar aracılığıyla önlemler sonucu sistem içine alınmaya çalışılmıştır. Halen devam etmekte olan bu sürecin, daha bir dizi düzenlemeye ihtiyaç duyduğu da açıktır. 


\section{Kaynakça}

ADRIAN, Tobias ve Ashcraft Adam B., Shadow Banking: A Review of the Literature, Federal Reserve Bank of New York Staff Report, No.580, (October, 2012)

ADRIAN, Tobias ve Ashcraft Adam B., Shadow Banking Regulation, Federal Reserve Bank of New York Staff Reports, No.559, (April, 2012)

ADRIAN, Tobias ve Shin, Hyun Song, The Shadow Banking System: Implications for Financial Regulation, Federal Reserve Bank of New York Staff Report, No.382 (July, 2009)

BANDT, Oliver De ve Hartmen, Philipp, Systemic Risk: A Survey, European Central Bank Working Paper, No.35, November, 2000)

Bank For International Settlements, Supervisory farmework for Measuring and Controlling Large Exposures, (April, 2014)

CLAESSENS, Stijn ve Retnovski, Lev, What Is Shadow Banking? IMF Working Paper, 14/25, (February, 2014)

CLAESSENS, Stijn ve Diğerleri, Shadow Banking: Economics and Policy, IMF Staff Discussion Note, 12/12, (December 4, 2012)

DEMİRGÜÇ, Kunt-Aslı ve Detragiache, Enrica, Financial Liberalization and Financial Fragility, Policy Research Working Paper, No:1917, World Bank, 1998

DİNÇ, Yusuf, Gölge Bankacılıktan Repolar Bankacılığa Geçiş, Özel Finans Kurumları Örneği, M.Ü. Bankacılık ve Sigortacılık Enstitüsü, Yayınlanmammış Doktora Tezi, 2015

DORUK, Ömer Tuğsal, Gölge Bankacılık ve Türkiye, Türkiye Bankalar Birliği, Yayin No. 300, İstanbul, 2014

Financial Crisis Inquiry Commission, (FCIC), Shadow Banking and the Financial Crisis, Preliminary Staff Report, 2010

Financial Stability Board, Strenghtening the Oversight and Regulation Shadow Banking, 2012

Financial Stability Board, Regulatory framework for haircuts on non-centrally cleared securities financing transactions, (14 October, 2014)

Financial Stability Board, Global Shadow Banking Monitoring Report, (30 October 2014)

GORTON,Gary ve Metrick, Andrew, "Securitized Banking and The Run on Repo", Journal of Financial Economics, 104 2012, s.425-451

GRUNG Moe, Thorvald, Shadow Banking and the Limits of Central Bank Liquidity Support: How to Achieve a Better Balance between Global and Official Liquidity, Working Paper, No:712, Levy Economics Institute of Bard College, 2012 , 
Institute of International Finance, "Shadow Banking": A Forward Looking Framework For Effective Policy, (June, 2012)

International Organization of Securities Commissions, Policy Recommendations For Money Market Funds, Final Report, 07/12, (October, 2012)

KAMINSKY, G.L. ve Secmukler, S.L., Short-Run Pain, Long Run Gain: The Effects of Financial Liberalization, IMF Working Paper, WP/03/34, Washington, DC: International Monetary Fund, 2003

KANSU, Aydan, Konut Balonundan Finansal Krize; ABD Mortgage Krizi, Scala Yayıncılık, İstanbul, 2011

KODRES, Laura E., "What is Shadow Banking?", Finance and Development, 50/2, (June, 2013), s. 42-43

KRUGMAN, Paul, Bunalım Ekonomisine Geri Dönüş ve Küresel Kriz, Çev: Neşenur Domaniç, Literatür Yayınları, No.60, İstanbul

KURTOĞLU, Ramazan, Küresel Ekonomik Kriz ve Yeni Dünya Düzeni, İstasyon Yayınları, İstanbul, 2011

LANGVOORT, Donald C., "Global Securities Regulation after the Financial Crisis" Journal of International Economic Law, 13/3, 2010, s.799-815

MC CULLEY, Paul, “Teton Reflection”, Global Central Bank Focus Series, PIMCO, (August/September, 2007), s.1-4

MISHKIN, Frederic S.,ve Eakins, Stanley, Financial Markets and Institutions, Fourth Edition, Addison Wesley, 2003

MISHKIN, Frederic S., The Economics of Money, Banking and Financial Markets, Sixth Edition; Addison Wesley, 2000

OJO, Marianne, Financial Stability, new macro prudential arrangements and shadow banking: regulatory arbitrage and stringent Basel III regulations, MPRA Paper, No.31319, (June, 2011)

ÖZDEMİ, Bilge Kağan, Finansal Küreselleşme ve Krizler, Seçkin Yayıncılık, No.128, 1. Basım, Ankara, 2013

POZSER ve diğerleri, Shadow Banking, Federal Reserve Bank of New York Staff Report, No: 458, (July, 2010)

POZSER ve diğerleri (2010), Shadow Banking, Federal Reserve Bank of New York, Economic Policy Review, (December 2013)

ROUBINI, Nouriel ve Mihm, Stephen, Kriz Ekonomisi: Dünya Ekonomisinin Çöküşü ve Geleceği, Çev: Işıl Tezcan, Pegasus Yayınları, İstanbul, 2011

SCHWARCZ, Steven L., "Regulating Shadow Banking", Review of Banking\&Financial Law, Vol. 31, (2011-2012), s. 619-642

SHENG, Andrew, Central Banking in an Era of Quantitatise Easing, Working Paper, No. 684, NY, Levy Economics Instute of Bard College, 2011 
STEIN, Jeremy C., "Securatization, Shadow Banking and Financial Fragility” Deadalus, (Fall, 2010), s. 41-51

STEFANINI, Filippo, Investment Strategies of Hedge Funds, West Sussex, John Wiley \& Sons Inc., 2006

TCMB, Finansal İstikrar Raporu, sayı: 19, (Kasım, 2014) 